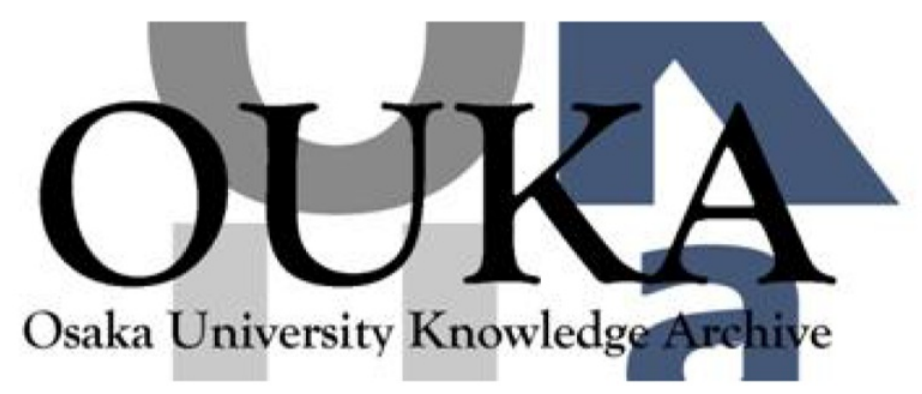

\begin{tabular}{|c|l|}
\hline Title & $\begin{array}{l}\text { Preface : 8th China-Japan Joint Nuclear Physics } \\
\text { Symposium }\end{array}$ \\
\hline Author(s) & $\begin{array}{l}\text { Liu, Weiping; Hatanaka, Kichiji; Zhu, Shengyun } \\
\text { et al. }\end{array}$ \\
\hline Citation & AIP Conference Proceedings. 1533 p. 1-p. 1 \\
\hline Issue Date & $2013-05-13$ \\
\hline oaire:version & VoR \\
\hline URL & https://hdl. handle.net/11094/51217 \\
\hline rights & ○ 2013 AIP Publishing \\
\hline Note & \\
\hline
\end{tabular}

Osaka University Knowledge Archive : OUKA

https://ir. Library. osaka-u. ac. jp/

Osaka University 


\section{PREFACE: 8th China-Japan Joint Nuclear Physics Symposium}

The $8^{\text {th }}$ China-Japan Joint Nuclear Physics Symposium (CJJNPS 2012) was held successfully on 15-19 October 2012 at the Beijing International Convention Center, Beijing, China. This symposium was organized by China Institute of Atomic Energy (CIAE).

The Symposium maintained its general spirit and intention of the previous symposiums. The scientific subjects discussed at the symposium covered a wide spectrum of basic and applied nuclear physics researches. The symposium consisted of the plenary sessions only in which all invited talks and oral presentations were given. This made it possible for the participants to share all talks and discussions. 29 Japanese scientists and 41 Chinese scientists participated in the symposium. There were 52 (26 for each side) invited talks plus 10 oral presentations given by Chinese students. The invited talks covered most of the frontiers in nuclear physics and summarized recent progress achieved by nuclear physics community in China and Japan.

We would like to express our sincere thanks to all participants for your great contributions to the success of the symposium.

We are very grateful to all members of the Advisory Committee and the Organizing Committee for the advice on the organization of the symposium and the recommendation and selection of the invited speakers and oral presentations.

The special thanks are due to the Symposium Secretariat for the efficient work and dedication in the preparation and organization of the symposium.

The publisher of the symposium proceedings, American Institute of Physics, is acknowledged with our deep appreciation.

Finally, we acknowledge the sponsorship and financial supports of National Natural Science Foundation of China, China Center of Advanced Science and Technology, Chinese Nuclear Physics Society, China Institute of Atomic Energy, State Key Lab of Nuclear Physics and Technology (Peking University), Institute of Modern Physics (CAS), and Shanghai Institute of Applied Physics (CAS).

Editors

Weiping Liu, Shengyun Zhu, K. Hatanaka and A.Nori

March 22, 2013

8th China-Japan Joint Nuclear Physics Symposium

AIP Conf. Proc. 1533, 1-1 (2013); doi: 10.1063/1.480676

(c) 2013 AIP Publishing LLC 978-0-7354-1157-9/\$30.00 